\title{
MYATONIA CONGENITA OF OPPENHEIM *
}

\author{
AUGUST STRAUCH, M.D. * \\ CHICAGO
}

Since Oppenheim ${ }^{1}$ has described and outlined the clinical picture of this disease, a number of subsequent observations by this author and others have broadened the clinical aspect, adding new features to those first described.

Some observations were made, in which not only the muscles of the extremities were involved but also those of the neck and back; and in a series of cases the flaccid pseudoparalysis involved not only the musculature of neck in addition to the more commonly affected extremities, but also that of the whole trunk simultaneously, so that with the exception of the diaphragm all muscles supplied by the spinal nerves appeared paralytic.

The assertion that the muscles supplied by the cranial nerves remain intact in this disease had to be modified as the result of additional observations. A certain degree of participation of the cranial nerves especially of the facialis is in a few histories at least cursorily indicated. Pollak ${ }^{2}$ published a report of a well-observed case with involvement of the musculature of the facial and hypoglossus nerves in addition to the affection of all the spinal nerve muscles with the exception of the diaphragm. Cases of facial affection are described by Tobler, ${ }^{3}$ Collier and Wilson. ${ }^{4}$

\section{REPORT OF CASE}

The following case seen by me this year deserves here a more detailed description, not only because it adds to the small series last mentioned, but also for reasons later to be dwelt on :

History.-Second child, girl, born in America, April 5, 1914, of healthy Russian Jew parents. Their first baby died when 3 weeks old, presumably from cephalematoma, which possibly became infected, as baby was paralyzed before death. Family history negative; no intermarriage. Spontaneous normal birth at full term. Mother had felt quickening during this pregnancy as in the first. The new-born, according to a woman friend, cried loudly immediately after birth, and was able to move during the first week of life;

* From the Central Free Dispensary, Rush Medical College, Chicago.

1. Oppenheim: Monatschr. f. Psychiat. u. Neurol., September, 1900, viii ; Berl. klin. Wchnschr., 1904, No. 10, p. 255 ; Lehrbuch der Nervenkrankheiten, Edition 5, Part 1, p. 242.

2. Pollak: Arch. f. Kinderh., 1910, liii, 373.

3. Tobler, L.: Ueber kongenitale Muskelatonie (Myatonia congenita Oppenheim), Jahrb. f. Kinderh., 1907, Ivi, 33.

4. Collier and Wilson: Amyotonia Congenita, Brain, 1908, xxxi, 1. 
the mother herself can make no statement on this point. She remembers at least, however, that in the second week of its life the baby moved only a little and very slowly and was completely paralyzed from the third week. The baby's cry was only a low, feeble one, the facial muscles showing no contractibility, "it cried only with its voice, but without its face." Abdominal respirations were labored. She was always a quiet baby. Stools were irregular, constipated, appetite and sleep good; breast-fed. These conditions did not change noticeably with the exception that the baby has exhibited during the last five or eight days a smile, and a slow, feeble mimical action of the face when crying.

Examination.-July 4, 1914: Girl, well nourished, face of healthy color. Panniculus adiposus well developed, skin warm, of healthy rosy tint. The baby lies on its back with all extremities immovable; when lifted up, they drop as lifeless to the pillow. The legs are rotated outwardly. Only very minimal slow, feeble movements of the fingers, toes and ankle-joints, spontaneously or on needle-pricks, to which the baby responds with very feeble crying. The abdomen is very prominent, tympanitic, the wall very flabby and soft. Respirations very frequent, from 70 to 80 per minute, irregular, abdominal, the diaphragm acting vigorously with marked inspiratory protrusions of the upper part of the abdomen and with retractions of the lower part of the thorax. The hand laid on the abdomen meets a marked resistance from the protrusion during inspiration. If the child is lifted up underneath the shoulders, the latter are pushed up to the ears on account of the flabbiness of the tissues; the arms and legs swing in complete flaccidity, the right arm thereby rotates into somewhat extreme position, as if without sufficient hold in its shoulder-joint. In the other joints of the extremities there is to be noted no hypermobility. If the body is brought into sitting position, the head on account of weakness of the neck musculature wabbles and drops helplessly to any side into extreme positions as in a cadaver, the trunk falls forward, forming a marked kyphosis. The limbs are full and round. The tissues of the upper extremities are markedly flaccid, so that the muscles are not discernible from the panniculus adiposus; those of the lower extremities that are well developed, have an almost normal turgor; their panniculus adiposus is solid and the underlying musculature can be palpated only very indistinctly. There is nowhere any atrophy to be noted. Though the face shows good muscular contractions during crying, yet these occur with appreciable slowness, and in the quieter intervals the infrequency and feebleness of the mimic display gives to the face a certain immobility and blank expression. Smiling occurs only very rarely and very feebly. Both eyes follow a flame or bright object; in lateral positions the bulbs show horizontal nystagmus, when fixating. Pupils react promptly to light. The baby recognizes its mother. $\mathrm{My}$ finger introduced into the baby's mouth causes a vigorous contraction of the lips and pressure by the sucking tongue. Stools constipated, appetite normal.

Reflexes.-Patellar reflex, Achilles-tendon reflex, Babinski, reflexes of the abdominal wall and soles of the feet are entirely absent, biceps-tendon reflex doubtful. No fibrillary contractions. No mechanical irritability of the muscles of the extremities on tapping with the percussion hammer.

Electric irritability: The neuromuscular irritability, examined on the extremities and trunk with strong faradic current is entirely absent; also no response to single shocks. (Galvanic test see July 25.)

A gross lesion of the sensibility can be excluded; but one's impression is that crying is less on faradic irritation of the lower extremities than of the upper, and that the patient bears strong faradic stimuli easily.

Treatment.-Daily faradic treatment, massage and sea-salt bath.

Course of Disease.-July 21: Baby moves the left arm occasionally, being able slowly to bring the hand spontaneously even to the mouth, and hold a morsel of bread. Very rarely the right arm is moved, slowly and only slightly in the elbow. The toes and fingers seem to show a slight improvement of mobility, if there is any change at all. 
July 25: Mother makes the statement that the baby can be induced to smile more easily. The crying is somewhat louder, and when quiet there is a beginning of a certain mimic display. Electric reaction: The examination of the muscles of the abdomen and the extremities reveals a complete lack of (neuromuscular) reaction on strong faradic current. The small muscles of the dorsum pedis contract moderately on strong galvanic current stimulation; quadriceps cruris and the muscles supplied by the peroneus nerve contract feebly. The contractions, however, are quick and short, not as in degeneration. The cathode closure contraction is somewhat stronger than the anode closure contraction.

July 29: During longer observation baby shows infrequency or almost entire absence of mimic display, but when pricked painfully shows good contractions of the facial muscles in crying. Horizontal nystagmus present especially in lateral positions of the eyeballs in fixating. The baby's legs are still motionless under ordinary conditions, but on several occasions they have been brought actively side to side in the bath, when previously they had been crossed over the shin-bone by the mother or passively bent in the knee-joint.

August 5: Baby is able to flex and somewhat extend the knee and hipjoints when in the bath, not otherwise. There is a decided improvement of both arms; occasional movements also are possible in both shoulder-joints, though less in the right one. Nystagmus. Crying with feeble voice. Respiration abdominal.

August 11: Condition the same: Crying very feeble. Spontaneous mimic display rare. Slight edema of dorsum pedis on both sides. The tissues of the legs are softer than before.

September 4: A moderate degree of flabbiness of the tissues of the legs has become evident; otherwise the condition is the same.

Summarizing the principal clinical features, we have flaccid pseudoparalysis of the muscles of the extremities and the trunk with the exception of the diaphragm, and an involvement of the facial muscles, with a tendency toward improvement. There is absence of the faradic and diminution of the galvanic irritability of nerves and muscles, but no atrophy. Skin-reflexes and tendon-reflexes are absent.

By this symptom-complex this case can easily be identified with the clinical picture of Oppenheim's myatonia congenita whose features may be reproduced here, before I dwell on a few factors of my case that are worthy of special consideration.

\section{SYMPTOMATOLOGY}

The disease occurs in the earliest infancy without known causes. That the beginning may occur during the intra-uterine life is indicated by the frequent statement of the mothers that during pregnancy they had felt no movements of the child. The symptoms exist from birth and in most cases are noted during the first days of life. With attention lacking or inefficient, the conditions may escape the notice of the family for weeks or even months until the failure of the baby to learn to stand or walk reveals the motor disturbance, as is also often the case in congenital cerebral paralysis (paraplegia) or early poliomyelitis anterior. In a few cases, in which even under good observation the symptoms were not manifest at birth, various diseases as bronchitis, 
pneumonia $\left(\right.$ Leclerc $\left.{ }^{5}\right)$ or diarrhea $\left(\mathrm{Comby}^{6}\right)$ soon caused their appearance. In such cases we may consider these intercurrent affections partly responsible through their general weakening result, only in making the manifestations of myatonia more conspicuous. Yet Rosenberg $^{7}$ observed a case in which the weakness of the legs appeared as late as in the eleventh month; Collier and Wilson ${ }^{4}$ report a similar observation and conclude that the disease may develop at any time in an apparently normal child in the first year of life.

The most conspicuous feature is the inactivity of the child and the flaccidity of the musculature. The affected extremities, the arms often and the legs invariably and in a greater degree, lie on the pillow as if paralyzed, because of the extreme weakness of the musculature; they remain motionless in the most uncomfortable positions in which they are brought during the examination. Perhaps the distal parts, namely, the fingers and toes, retain a slight spontaneous residual mobility or on needle-pricks. The movements in the other joints, should they be present, are slow and weak in the more pronounced cases, the muscular contractions being without energy and real locomotor effect. The limbs, lifted by the examiner, drop on the support as if lifeless. The affected muscles are as a rule markedly flaccid, hypotonic or atonic, of soft consistency, but not atrophic, as in poliomyelities anterior, or in neuritic paralysis; nor are fibrillary contractions to be observed.

It is impossible to distinguish by the touch between panniculus adiposus and muscles; the structures from the skin down to the bone seem to be one soft homogeneous substance. In a few cases, however, a certain degree of reduced volume of the muscles has been clinically noted, as by Batten, Collier and Wilson, Marburg and Schlivek; which fact does not surprise us, if we consider the inactivity of the muscles more or less absolute - apart from the nature of the disease. In other cases an abundant development of the panniculus adiposus renders it impossible to make a decision, and marked reduction of muscle with proliferation of connective and fat tissue has, been revealed anatomically in cases in which the clinical appearances indicated well-developed muscles.

The joints may be loose, flaccid and more or less flail-like, so that the limbs are passively movable like loose appendages. Where the back and neck musculature is involved, the body, if brought to a sitting position, will fall forward and double up "as if made of rubber" with the formation of an extreme kyphotic curvature of the spinal column, and the head will wabble and fall to any side. Standing is impossible,

5. Leclerc: Gaz. d. hôp., 1907, No. 141.

6. Comby: Bullet. Soc. pédiatr. de Paris, October, 1907, p. 149.

7. Rosenberg: Ueber Myatonia congenita, Deutsch. Ztschr. f. Nervenh., 1906, xxxi, 130 . 
as the lower extremities collapse helplessly. Where the respiratory (intercostal) muscles participate, the respiration has lost its costoabdominal character and becomes purely abdominal, the diaphragm acting vigorously in compensation. The weakness of the abdominal wall musculature manifests itself in more or less marked softness, protrusion and flabbiness of the abdomen and may cause constipation.

The reflexes are as a rule absent or diminished; likewise the neuromuscular irritability to both currents, but degeneration reaction will not be found. The sphincters of anus and bladder and the vasomotors are normal, the sensibility rarely (cases of Rothmann, ${ }^{8}$ Collier and Wilson ${ }^{4}$ ) is slightly affected. The affection in its typical form is the antipode of Little's disease.

The course of the disease is chronic with a tendency toward improvement, a part of the more severe manifestations being capable of a gradual reparation during months or years, though perhaps in no case as yet has a complete recovery been observed. The improvement is mostly slow, to be of any amount, takes years, but even after a standstill for years, improvement can take place. The upper extremities apparently always recover first, and may gain even a normal function. The disease is not dangerous of itself, but it exposes the individual - as dystrophia musculorum progressiva — in a high degree to pulmonary affections, and their prognosis is markedly impaired through the weakness of the respiratory muscles. In fact, that pneumonia and bronchitis are among the chief causes of the high death-rate among these individuals is no mere accident. It is worthy of note that this clinical picture has not been observed in the adult, a fact partly explainable by the great dangers of accidental intercurrent diseases.

The more limited the atonia is, either from the beginning or as the result of improvement, the more limited and altered will be this picture of infirmity. Further attention should be given to the existence of rudimentary, abortive forms of the disease. From the literature we note the fact that considerable differences in the intensity of the symptoms undoubtedly exist. In some cases with hypotonia there were indeed only minor degrees of paresis. It is probable that some hypotonic conditions in infants may have a cause identical to that of the fully developed, pronounced pictures of myatonia congenita, especially if muscular weakness is manifested in the lack of energy of some movements.

\section{NATURE AND PATHOLOGY}

Oppenheim referred the myatonia to a retardation of development of the musculature, without excluding the possibility of a developmental retardation of certain nerve centers, especially of the ganglia

8. Rothmann: Monatschr. f. Psychiat. u. Neurol., 1909, xxv, Ergänzungsheft, p. 161 . 
of the anterior horns and their function. The possibility of a gradual development toward normal or almost normal function, but also of an aggravation - though very rare - is admitted.

The anatomic findings have been various; they place the affection near the group of the primary myopathias - dystrophia musculorum progressiva - which latter have a close relationship to the spinal myopathias; but clinical reasons so far do not allow us to classify myatonia with dystrophia progressiva. The most frequent alterations concern the musculature. The pathologic-anatomic findings of Spiller are in support of Oppenheim's view; the affected muscles were little developed amid an hyperplastic interfibrillary fat tissue; the musclefibers were very narrow, their longitudinal striation indistinct; the nervous system was intact.

Rothmann $^{8}$ observed a marked proliferation of the interstitial connective and fat tissues; the muscle-fibers were partly atrophic. Also Reyher and Helmholz found the muscles, especially of the legs, deeply affected; the fibers were partly thin, partly hypertrophic, their transversal striation partly indistinct, partly lacking.

In the cases of Baudouin ${ }^{9}$ and Collier and Holmes, ${ }^{10}$ the muscular changes resembled much those in primary myopathias. They observed also congenital hypoplasia of the cells of the anterior horns. In some of these cases the cells were markedly small and underdeveloped; or their number was decreased, but without any sign of inflammation; the peripheral nerves had defectively developed medullary sheaths, a condition which was considered a sign of underdevelopment.

In Rothmann's case there was extensive atrophia (Schround) of the motor ganglia throughout the medulla spinalis. Also the white substance was not intact. The cross-section of the medulla spinalis was small in toto. The transverse section of the peripheral nerves was very narrow ; there were also pathologic changes in the nuclei of a few cranial nerves (hypoglossus, vagus); these, however, had given no clinical symptom.

Thus really the affection may concern the whole peripheral neuron, the aplasia or hypoplasia involving in the one case this, in another case that segment of the neuron, including the muscle.

Bing, ${ }^{11}$ differing from Spiller, ${ }^{12}$ found a normal structure of an excised particle of muscle with the exception of perhaps a somewhat increased number of nuclei, and conceives the nature of the disease

9. Baudouin: La myatonie congénitale (maladie d'Oppenheim), Semaine méd., 1907, xxxvii, 241.

10. Collier and Holmes: Brain, 1909, xxxii, 269.

11. Bing: Ueber atonische Zustände der kindlichen Muskultatur; vorläufige Mitteilung, Med. Klin., 1907, iii, 10.

12. Spiller: Myatonia congenita, Penn. Med. Bull., 1905, xvi, 342. 
to be an inhibition of the development of the spinocerebellar nervetracts that regulate the tonus.

Vierordt thinks of a diminution of functional responsiveness for central and peripheral stimuli of the cells of the gray anterior horns of the medulla. The clonic spasms in the cases of Sorgente ${ }^{13}$ would be explained by stimuli of maximum intensity.

Kaumheimer ${ }^{14}$ draws the conclusion, from the histologic examination of a case, that myatonia is an entity which must be considered either as a toxic or endogenic affection, while the doctrine of inhibition of development or of inflammatory processes being the pathologic basis of myatonia must be discarded. The process has not necessarily found its completion at birth, but may cause alterations of the muscles even months later.

\section{TREATMENT}

The tendency of the disease toward partial or more pronounced spontaneous improvement renders it difficult to decide the contributing effect of any treatment; in addition to this, the descriptions of most cases in the literature represent merely snapshot pictures, so to speak. But it often seems as if a more pronounced improvement had taken place during treatment with electricity and massage, extended persistently over a long period.

\section{COMMENT ON AUTHOR'S CASE}

My own case is of great interest because of the involvement of the facial muscles, manifesting itself in lack or weakness of the mimic display; this was replaced by a certain degree of immobility, which improved before the other symptoms. The crying was markedly feeble, which fact finds its explanation in the involvement of the respiratory muscles, especially of the expiration musculature, a symptom also observed by Pollak, ${ }^{2}$ Berti, ${ }^{15}$ Baudouin, ${ }^{9}$ Lugenbühl. ${ }^{16}$ The high frequency of the respiration and the vigorous inspiratory protrusion of the abdomen point also to a weakness of the intercostal muscles, that show retractions during inspiration.

It is noteworthy that, though the pseudoparalysis was more marked and more persistent in the lower extremities, their turgor or tonus was almost normal for the first four months, while the entire upper extremities with their more visible improvement manifested a pro-

13. Sorgente: Due casi di atonia muscolare di Oppenheim, Pediatria, 1906, xiv, 358 .

14. Kraumheimer: Jahrb. f. Kinderh., 1913, lxxviii, Ergänzungshaft, p. 170.

15. Berti: Contributione alla atonia muscolare congenita di Oppenheim. 3. adunanca della seziona Emiliana della Societa Italiana di pedriatria, Dec. 4, 1904 ; Pedriatria, 1905, p. 134.

16. Lugenbühl: Deutsch. med. Wchschr., 1907, p. 1439. 
nounced atonia; the flaccidity of the shoulder-blade musculature permitted passive motions upward or medianward to the ears. While Cassirer $^{17}$ claims that in most cases the proximal muscles of the extremities are less affected than the distal ones, a number of cases have presented the reverse conditions (Kaumheimer, ${ }^{14}$ Kundt, ${ }^{18}$ Rosenberg $\left.^{7}\right)$. To the latter group belongs also my case; only the fingers and toes were slightly movable at the first observation. The explanation of this may be that for the movements of small parts, such as the distal ends of the extremities, less strength is required. Similarly I could observe the first signs of improvement in the mobility of the legs while the baby was submerged in the bath, which diminished sufficiently the motion-inhibiting effect of friction and gravity for the at first only minimal functional capacity of the legs. The very obvious flabbiness of the abdominal wall and the softness of the tympanitic abdomen indicated an involvement of this musculature; there was also constipation. The neck and back musculature being involved, the pseudoparalysis concerned all the spinal nerve muscles with the exception of the diaphragm.

Nystagmus, as in my case, was noted also by $\mathrm{Koch}^{19}$ and was referred by him to a congenital defect of eyesight. Whether this ocular symptom in my case should be considered as a manifestation of a congenital weakness of the external muscles of the bulbus, similar to that observed in lesser degrees of paresis of an extra-ocular muscle, or of a functional exhaustion, similar to the nystagmus in miners, or whether it should be regarded of central origin, cannot be decided with certainty. I am inclined to consider in my case the presence of weakness of extra-ocular muscles as a condition analogous with those of other muscles, affected in myatonia. A defect of eyesight in my case may be excluded by the fact that the child fixates well and recognizes persons, responding after improvement to the smile of the mother.

An interesting feature resulted from the electric examination of the nerves and muscles; though the irritability even to strong faradic currents was completely lost, there was nevertheless present a somewhat lessened irritability to the galvanic current; differing from degeneration reaction, however, the contractions were quick, short, though weak, and the cathode closure contractions were somewhat stronger than the anode closure contractions. As usually reported, the irritability of the muscles and nerves to the galvanic as well as the faradic currents in myatonia congenita of Oppenheim is found either absent or much decreased; in the case of Bing ${ }^{11}$ the reaction was almost normal; in

17. Cassirer: Lewandowsky's Handbuch der Neurologie, 1911, ii, 230.

18. Kundt: Ueber Myatonia congenita, Inaug. Diss., Leipsic, 1905.

19. Koch: Jahrb. f. Kinderh., 1913, Ixxviii, Ergänzungsheft, p. 305. 
that of Muggia ${ }^{20}$ there was normal neuromuscular irritability. No qualitative alterations of the contraction formula is to be observed; Cassirer, Oppenheim, Rosenberg and others never found degeneration reaction; Rothmann, however, saw a rather sluggish contraction in his case.

Collier and Wilson described a special form of alteration of the electric reaction, which they declared was characteristic of myatonia, and they termed it "amyotonic reaction," and Chène concurs in this view. According to the observations of these authors the muscles react to the faradic current with diminished irritability, while to the galvanic current not only are the formula and character of the contractions normal, but also the quantitative alteration is only moderate. This special reaction is declared to be demonstrable to a certain degree in every muscle, most markedly, however, in the muscles most affected by the pseudoparalysis. The reverse of this modus of electric reaction was encountered by Koch, viz., the decrease of irritability was more marked for the galvanic than for the faradic current.

There exists no differential diagnostic difficulty in our case. Poliomyelitis must be excluded by the congenital character, the absence of febrile beginning, of vasomotor anomalies, the absence of degenerative atrophy and degeneration reaction, and by the symmetry and extent of the motor disturbances. The muscles in poliomyelitis recover rather by groups and the stage of reparation is much shorter. Pseudoparalysis rachitica is out of the question.

The extreme rarity of acute generalized polyneuritis at this age militates against this disease, also the absence of an etiologic factor (diphtheria), of pain or sensible disturbances of a higher degree; the absence of disturbances of the heart-action and deglutition, and the lack of degenerative atrophy.

In dystrophia musculorum progressiva we would expect a later onset, possibly a hereditary factor, gradual progress, the presence of localized myatrophia, perhaps hypertrophic and pseudohypertrophic muscles and no participation of the distal muscles, especially of hand and foot, which is rare in dystrophia. In Werdnig-Hoffmann's spinal atrophy of muscles we would have steady progress, an exact localization of atrophic paresis (proximal distribution) and degenerative reaction.

4557 Broadway.

20. Muggia: Adunanza della sezione Piemontese della Societa Pedriatrica Italiana del febbraio, 1903; Pedriatria, 1903, p. 179. 